\title{
La función del modelo de "comunicación casino" en la crisis del sistema neoliberal contemporáneo
}

\author{
Javier Esteinou Madrid* \\ Universidad Autónoma Metropolitana-Unidad Xochimilco
}

El modelo de "economía casino" que originó la crisis económica contemporánea en el año 2008, funcionó gracias a que construyó un modelo de "comunicación casino" que promovió los valores bárbaros del capitalismo salvaje y fomentó la compra de "inversiones basura", derivados financieros de alto riesgo y productos bursátiles tóxicos paralelos que durante varios años generaron dicho modelo especulador. Por ello, la verdadera corrección de tal hundimiento económico no se arreglará con la simple inversión financiera de los Estados nacionales, sino que se solucionará con el saneamiento profundo de las raíces ético morales que lo originaron.

Palabras claves: crisis neoliberal, economía casino, derrumbe moral, comunicación casino, crisis comunicativa.

The "casino economic model", that caused the contemporary economic crisis in 2008, worked out because it was able to create a "casino communication model" that promoted the barbaric values of savage capitalism, and encouraged the acquisition of "trash" investments, high-risk financial derivatives and other monetary toxic products that for years generated this speculative model. Therefore, a real solution for the economic collapse requires more than simple financial investments of the national states; it is necessary to clean up the moral and ethic heart that originated it.

Key words: neoliberal crisis, casino economy, moral crumble, casino communication, communicative crisis.

* Investigador titular del Departamento de Educación y Comunicación de la Universidad Autónoma Metropolitana-Unidad Xochimilco, México, D.F. Correo electrónico: jesteinou@prodigy.net.mx 


\section{EL FRACASO DEL NEOLIBERALISMO CONTEMPORÁNEO}

Después de la caída del Muro de Berlín y del ocaso de los países socialistas en la década de los años ochenta, los gobiernos neoliberales, especialmente de Occidente, formularon el fin de la era del Estado interventor o rector que defendía el prototipo de economías centralmente planificadas, y se declaró el triunfo del modelo de la dinámica mercantil con su respectivo orden derivado de la acción de la "mano invisible del mercado" regido por el proceso crecientemente desregulado de la oferta y la demanda. Este fenómeno se consolidó a tal extremo triunfalista que permitió que dichos regímenes de mercado y las clases políticas neoindustriales declararan la etapa del "fin de las ideologías", en la cual la fase del desarrollo histórico del prototipo del mercado había triunfado sobre todos los otros modelos de desarrollo existentes a lo largo de la historia universal. En esta forma, gradualmente desde la década de los años setenta se abandonaron los acuerdos establecidos en 1944 en la reunión de Bretton Woods por los principales países desarrollados de Occidente, en la que se acordaron las bases para el funcionamiento normado del nuevo orden financiero internacional a través del Estado, después de la Segunda Guerra Mundial, y se le dio total libertad al fundamentalismo de la dinámica del mercado para que dirigiera a las sociedades modernas. Así, en el terreno económico político, paulatinamente se creó la etapa del pensamiento único, donde se abandonaron los principios del Estado regulador keynesiano, y se permitió que la lógica del "dios mercado", con su dinámica del "dejar hacer dejar pasar" y de sus leyes operativas, fijaran las pautas, los ritmos y los equilibrios de evolución de las comunidades humanas. ${ }^{1}$

En este contexto, desde los años ochenta la dinámica de la oferta y la demanda se convirtió en la ley desde la cual se reconstruyeron la mayoría de las sociedades contemporáneas en sus niveles económicos, políticos, sociales, culturales y espirituales. Dicha dinámica se declaró como el proceso económico perfecto que se dedicó a desmantelar los cimientos del viejo "Estado del bienestar" o "Estado benefactor" que había funcionado durante muchas décadas en el mundo occidental, y se formuló la filosofía del "Estado cero", cuyo principal argumento giró alrededor de la idea de reducir la presencia y la acción interventora del Estado a su mínima expresión, y dejar que fueran las fuerzas autónomas del mercado "autorregulado" las que definieran las características, la estructura y la dirección de las sociedades modernas en sus procesos económico-comunicativos y en otras áreas de lo público.

${ }^{1}$ Tras un nuevo paradigma. (2008). Revista Siempre, 2888, 8-12. 
Mediante este proceso, el Estado fue conquistado por el mercado y lo redujo a su mínima expresión en todos sus ámbitos rectores, convirtiéndolo en un simple gerente que administró los intereses y las ganancias desorbitadas del capital monopólico. Así, de instancia rectora de la sociedad en la fase neoliberal, el Estado se transformó en una simple herramienta protectora y administradora del gran capital para alcanzar sus intereses sacrificando las necesidades apremiantes de la mayoría de la sociedad. Con ello, los mercados funcionaron durante muchos años con plena libertad económica, con grandes privatizaciones de la esfera pública, con mínimos controles estatales y con poca supervisión gubernamental, pues se argumentó dogmáticamente que la dinámica del mercado por sí misma autorregularía y autocorregiría todos sus procesos económicos y sociales, e incluso nivelaría sus posibles desviaciones. ${ }^{2}$

Sin embargo, desde septiembre de 2008 se gestó un trágico periodo económico mundial que demostró el rotundo fracaso de la aplicación de las políticas neoliberales del mercado salvaje a nivel planetario, por la instrumentación prolongada de las directrices pragmáticas del neoliberalismo feroz basadas en el "dejar hacer, dejar pasar" y en la filosofía del "Estado cero". La especulación bursátil, ocasionada por la ambición irrefrenable como resultado de la ausencia de rigurosas normatividades regulatorias y de supervisiones responsables por parte del gobierno estadounidense durante el periodo presidencial de George W. Bush, y del gobierno inglés en el terreno financiero, superó las consecuencias de la crisis del ataque terrorista a las Torres Gemelas de Nueva York del 11 de septiembre del 2001, y generaron el mayor desastre económico que ha enfrentado la historia contemporánea desde el colapso de la Gran Depresión de 1929.

Así, se constató de nuevo que la estructura del mercado con su dinámica de la "mano invisible" por sí misma, sin contrapesos reguladores, no es capaz de crear un orden social armónico y, mucho menos, civilizatoriamente superior; por el contrario, lo que ocasiona son profundas anarquías estructurales con sus respectivas crisis económicas, políticas, sociales y psíquicas recurrentes, que devastan todas las áreas de la vida de las poblaciones.

La quiebra del sistema financiero internacional en 2008 demostró, una vez más, que el mecanismo de la sola autorregulación del mercado como herramienta de conducción social sin la acción de contrapesos compensadores, es un gran fraude de la teoría económica neoliberal, pues las evidencias históricas de repetitivos cracs sistémicos han señalado recurrentemente que no cuenta con bases conceptuales y operativas profundas para poder

${ }^{2}$ El castillo de naipes se derrumba. (2008, 5 de octubre). Revista Siempre, 2886, 17. 
funcionar. ${ }^{3}$ Con esto, podemos ver que el reinado del modelo desregulado neoliberal en el terreno monetario provocó el macrocaos económico más profundo en toda la historia del capitalismo moderno desde los años treinta, que desnudó y desarmó el paradigma autoritario del mercado que se impuso internacionalmente en las últimas décadas en casi todas las naciones del orbe, y que a su vez provocó el hundimiento del sistema financiero internacional y de los programas de crecimiento de todos los países del mundo durante varios años. Asimismo, con estos acontecimientos se constató que el modelo neoliberal estaba agotado; ${ }^{4}$ es decir, el colapso demostró que el modelo avanzado del capitalismo neoliberal llegó a sus límites históricos de autosostenimiento. De esta forma, y reconociendo la profundidad de este colapso civilizatorio, se puede decir que en el siglo XXI "la crisis de Wall Street fue para el mercado, lo que en el siglo XX la caída del Muro de Berlín y la quiebra del sistema marxista leninista fue para el comunismo" (Cela, 2008, p. 69).

\section{EL ORIGEN ÉTICO MORAL DE LA RECESIÓN MUNDIAL DE 2008}

Frente a la nueva crisis económica posmoderna que enfrentaron todas las sociedades contemporáneas, es muy importante precisar que, a diferencia de otras debacles tradicionales del sistema capitalista que se dieron en el siglo XX por el agotamiento recurrente de los ciclos económicos entre la producción y el consumo o entre la oferta y la demanda de mercancías o de capitales, esta nueva crisis no surgió originariamente por la contradicción clásica entre los factores económicos anteriores, sino que emergió por la variable primigenia de la súper ambición incontrolada de los agentes financieros de Wall Street, que fue la que desató de manera incontrolable tal derrumbe. Esta realidad se concretizó a través de movimientos especulativos que se practicaron en las principales plazas bursátiles del mundo, y por la ausencia de supervisiones estatales sobre los mismos por parte del gobierno estadounidense y de otras naciones.

Dicha práctica especulativa se inició en los Estados Unidos cuando la Reserva Federal (FED) bajó drásticamente las tasas de interés de 2002 a 2006 a los mínimos de los últimos 50 años, llevándolas hasta niveles de $1 \%$, con el fin de reactivar la economía de ese país después del colapso provocado por el ataque terrorista a las Torres Gemelas en Nueva York en septiembre de 2001. En este contexto de emergencias materiales, la banca

\footnotetext{
${ }^{3}$ EU ya no será más la potencia hegemónica. (2008, 28 de octubre). La Jornada, p. 17.

${ }^{4}$ La crisis global se debe a que el modelo capitalista está agotado. (2008, 1 de noviembre). La Jornada.
} 
estadounidense empezó un fuerte periodo de otorgamiento masivo de créditos muy bajos para incentivar al deprimido sistema económico, especialmente en el ámbito hipotecario.

De esta forma, con tal de ganar más clientela frente a sus competidores, durante muchos años la codicia del sistema bancario estadounidense autorizó de manera indiscriminada préstamos y más préstamos, sin ninguna supervisión, hasta llegar al extremo de ofrecer a los clientes las "hipotecas subprime" o "préstamos basura" o "préstamos Nina"; es decir, hipotecas de alto riesgo concedidas a la población que no contaba con ingresos, o con trabajo, o con activos para responder a esos compromisos materiales (no income, no job, no assets). ${ }^{5}$ Simplemente, por ejemplo:

... entre 2005 y 2007, entre préstamos hipotecarios y no hipotecarios, la banca norteamericana otorgó una cifra superior a los 4.5 billones de dólares; de los cuales $20 \%$ fueron concedidos a personas físicas sin capacidad de cubrir tales créditos, y para finales de 2008 éstos ya habían generado pérdidas superiores a los 516000 millones de dólares. ${ }^{6}$

Así, existieron recursos disponibles a tasas de interés muy bajas que formaban un entorno de gran rentabilidad para las empresas financieras y facilitaban la contratación de deuda para los productores, los constructores de casas y, en especial, para los consumidores.

La economía mundial crecía con exceso de deudas, con innovaciones bancarias y complejas transacciones de títulos; sin grandes presiones de inflación, generando, no obstante, fuertes desajustes internacionales en las cuentas comerciales, de capitales, y distorsiones del valor de las monedas. En este contexto, los analistas financieros y económicos en los bancos, organismos internacionales y profesores de abolengo en muchas universidades de todo el mundo, no veían prácticamente mayores riesgos en el hecho de que hubiera tan grandes facilidades de crédito en los mercados en dondequiera que se mirara. Los signos de riesgos en los que se incurría se mantenían convenientemente al borde de la pista donde actuaban los "magos del dinero" (Bendesky, 2008).

Sin embargo, el entorno que propiciaba el aumento del riesgo crecía de manera sostenida retroalimentado por las autoridades monetarias y regulatorias. Surgió un exceso de confianza por la reducción de controles, la minimización de los supervisores estatales y por la abundancia de intermediarios bursátiles que promovían la compra de los "activos tóxicos" de

\footnotetext{
${ }^{5}$ Hemos vendido nuestra alma al diablo por dinero. (p. 2). Recuperado el 28 de octubre de 2008, en la página web www.expansión.com

${ }^{6}$ Agencias calificadoras de riesgo en la mira. (2008, 16 de octubre), DW-World.de. Deutsche Welle. La otra visión, p. 1.
} 
los bancos. El entusiasmo prevaleciente no era cuestionado en esencia. Las ganancias eran grandes, entonces para qué moverse, y la fe en los mercados dominó las visiones predominantes. El equilibrio, que es el ambiente preferido de la teoría económica y de los funcionarios de los ministerios de Hacienda y de los bancos centrales, sería continuamente restablecido por la misma operación de los mercados. En tal marco histórico, la regulación y las normas se convertían en asuntos políticamente incorrectos (Bendesky, 2008).

Así, en el largo periodo de gobierno del expresidente George W. Bush en los Estados Unidos, para favorecer la expansión de los intereses de los grandes capitales se desmantelaron de manera sistemática los mecanismos de regulación más mínimos que limitaban la acción del capital financiero, controlaban la actividad de los bancos e impedían la creación de numerosos "instrumentos", con los cuales posteriormente se produjo una explosión de la "titularización" de las deudas que gestaron el derrumbe del sistema económico mundial. Mediante ello, se estableció una atmósfera con amplio libertinaje para que banqueros, corredores de bolsa, financieros, etcétera, pudieran operar y robar cuanto desearan, sin que sufrieran mayores consecuencias, pues casi toda acción financiera osada estaba permitida (Blanco, 2008, p. 14). La aplicación de estas políticas desreguladoras a finales del siglo XX dieron origen, en el terreno económico, al "Estado cero", donde éste ya no actuó como entidad rectora y reguladora de la economía, sino como un simple gerente o administrador de los fuertes intereses del gran capital mundial. De esta forma, el proceso económico fue regido por los principios autorreguladores del mercado salvaje, y no por las políticas planificadoras de los Estados nacionales, que es lo que justifica su existencia.

A través de este respaldo los "artífices monetarios" crearon una burbuja de crecimiento ficticio, especialmente en el sector de la vivienda, basado en el otorgamiento de crédito figurado o de falso capital que no contaba con respaldo material e institucional real. Este proceso se prolongó durante varios años, hasta que en septiembre de 2007 fue necesario que la Reserva Federal volviera a subir las tasas de interés hasta 5.25\%, para rescatar la fuerte caída que había experimentado el dólar ante la fortaleza que alcanzó el euro a nivel mundial. Así, ante la fuerte elevación de las tasas de interés, miles de deudores no pudieron pagar los préstamos contraídos anteriormente, y se generó una ola de insolvencia y de quiebras masivas que ocasionaron sustanciales pérdidas para los sistemas financieros (De León, 2008).

Para evitar absorber todas las pérdidas ocasionadas, los grandes bancos estadounidenses endeudados iniciaron en el circuito bursátil mundial la 
venta irresponsable y sin control de portafolios de valores o fondos económicos endeudados que ya no tenían "valor", y que se volvieron a revender una y otra vez en el sistema financiero internacional, para deshacerse del riesgo y la pérdida a largo plazo, hasta que estalló la quiebra de liquidez en las principales instituciones bancarias del mundo.

Otro de los recursos de protección que gestionó el sistema bancario para evitar más pérdidas, fue contratar múltiples seguros financieros internacionales con las más grandes aseguradoras mundiales, como la American International Group (AIG), que al momento del hundimiento financiero, también sucumbieron arrastradas por el colapso global.

La explosión de esta realidad generó, en primer lugar, una crisis financiera en la banca comercial, la banca de desarrollo y el mercado accionario; en segundo término, se transformó en crisis económica al impedir que empresas y particulares pudieran resolver sus problemas de deuda con la banca; en tercer lugar, el grave problema de deuda con la banca se trasladó a los sectores de la producción, del empleo, de la inversión, del comercio, etcétera. ${ }^{7}$ En cuarto término, se convirtió en fuerte anarquía social. Y finalmente, estalló en delicadas crisis políticas que debilitaron los mecanismos de gobernabilidad de los Estados nacionales.

Posterior al estallido de la insolvencia financiera, económica, social y política, el conflicto creció vertiginosamente a dimensiones gigantescas e inmanejables por los gobiernos y las instituciones internacionales, que se perdió la claridad analítica de las verdaderas causas morales y culturales del mismo, y sólo se observaron los espectaculares efectos materiales negativos de la quiebra mundial, que opacaron la rigurosa observación. Así, el desencadenamiento acelerado de este colapso arrastró la reflexión objetiva sobre el problema y sólo permitió que se vieran los orígenes económicos superficiales, escandalosos e inmediatos del mismo, nublando sus verdaderas causas psicológicas ético-morales profundas que silenciosamente le dieron vida.

Contrario a las explicaciones econométricas que sólo examinan los desajustes de los diversos elementos del circuito económico para entender la drástica crisis contemporánea, es muy importante destacar que todo este proceso partió de la existencia de una realidad ideológica previa. Dicha situación fue el ejercicio extremo del contenido de la mentalidad profunda del neocapitalismo basada en la aplicación de la cultura de la especulación, los valores de la ambición ilimitada, la codicia estructural, la avaricia de Wall Street, la acumulación sin freno, los prototipos del individualismo, el imaginario del enriquecimiento personal a corto plazo

${ }^{7}$ Primero EU... y después el mundo. (2008, octubre 5). Revista Siempre, 2886, 11. 
a costa de lo que fuera, el pensamiento del "dinero fácil", la psicología de la usura, la ausencia de ética en el mercado bursátil, la ideología del agiotismo, el abuso monetario sin consecuencias, el comportamiento financiero sin límites, las acciones económicas fraudulentas, la deshonestidad de los agentes reguladores, el fenómeno de la economía virtual, el estímulo de los mercados mediante la corrupción y la falta de regulación, etcétera, practicada durante años por los “yuppies financieros" y los funcionarios que los protegieron (Santa Cruz, 2008, p. 28). Tal fenómeno se dio con apoyo de las nuevas tecnologías informáticas de comunicación, y las interrelaciones bancarias globalizadas lo irradiaron a todo el mundo y se amplificó desproporcionadamente por la falta de regulaciones rectoras oportunas -inicialmente del gobierno estadounidense y, más tarde, del resto de los Estados nacionales contemporáneos-. Es decir, fue la aplicación hasta sus últimas consecuencias de la irresponsable cosmovisión de los yuppies a escala mundial la que hizo crisis y la que provocó que todas las naciones, en mayor o menor grado, fueran arrastradas a una severa recesión económica de larga y profundas consecuencias para todo el planeta. Esto significó, además, que dicho desastre nació en la aplicación irrestricta de los "valores culturales basura" fundamentales de la estructura ideológica y comunicativa del neocapitalismo financiero contemporáneo en su fase de globalización, que a su vez crearon los "valores financieros basura". Dichos "valores", después de aplicarse hasta su máximo extremo, llegaron a su límite de resistencia e hicieron crisis ocasionando una desestructuración de todo el sistema económico mundial, arrastrándolo a la hipertrofia del crecimiento.

En este sentido, el proceso de acumulación contemporánea que se dio en la etapa del neoliberalismo salvaje en los Estados Unidos y en el mundo en general en la primera década del siglo XXI, se logró debido a la aplicación irrefrenable de la mentalidad de la ambición de los agentes económicos que siempre aspiraron a acumular cada vez más como una forma moderna de "realización humana y sentido de la existencia", y a la ausencia de un Estado fuerte que colocara límites a esta tendencia compulsiva por el acaparamiento material. Dicha mentalidad fue el motor que propició que se practicara un liberalismo económico salvaje sin restricciones, cuyo único objetivo fue superar los niveles privados de concentración de capital previo que se habían alcanzado. Por consiguiente, fue en el ámbito cultural acéfalo y desregulado del sistema neoliberal donde se cultivó el germen de esta drástica crisis sistémica, que posteriormente se transmitió a las acciones cotidianas de los intermediarios financieros. En síntesis, la crisis de los valores económico-financieros de la sociedad contemporánea tuvo su colapso en el derrumbe de los valores culturales, morales, éticos y espirituales de 
los agentes del mercado y de las instituciones financieras contemporáneas que manejaron dichos recursos bancarios.

En este contexto, el candidato republicano a la presidencia de los Estados Unidos, John McCain, en su campaña electoral de 2008 para suceder en la Casa Blanca al presidente George W. Bush, denunció que "esta crisis fue el resultado de que en Washington y en Wall Street se premiaron la codicia y la corrupción" (Santa Cruz, 2008, p. 28); fue la exaltación y promoción gremial y colectiva de los comportamientos deshonestos y excesivos como valores del nuevo éxito de la moderna sociedad neoliberal. Por consiguiente, a diferencia de otras crisis económicas históricas, este estancamiento global no fue creado por deficiencias en el proceso económico de los países emergentes, sino que fue una crisis sistémica generada en los países centrales más desarrollados del capitalismo contemporáneo, ocasionada por el juego de los "especuladores irresponsables" del capital financiero, las inconsistencias de la dinámica de la autorregulación de los mercados salvajes y la debilidad interventora del Estado, que llevó al colapso a la economía mundial y marcó el final del modelo económico y político neoliberal que pregonaba las directrices de la ausencia de controles estatales. ${ }^{8}$

Este panorama complicó más la de por sí muy grave crisis de reservas económicas, pues ante la falsificación de la realidad económica por los órganos oficiales de fiscalización, los gobiernos y el público no supieron durante muchos meses cuál fue el nivel y la profundidad de la megacrisis que surgía en el neocapitalismo de principios del siglo XXI. Así, derivado de esta situación severamente amoral que engañó a más de la mitad del planeta, se produjo una profunda crisis de confianza internacional en las auditorías, en la función de las agencias calificadoras internacionales, en el papel de la banca de inversión, en los organismos de control gubernamentales, en las tesorerías corporativas, en la posibilidad de pagos de los cuentahabientes, en la responsabilidad de los políticos y en la capacidad de los gerentes de los sistemas financieros globales.

En este sentido, la desconfianza, la incertidumbre y el escepticismo de la población en las instituciones crediticias, en los órganos reguladores del Estado y en el modelo neoliberal de crecimiento del capitalismo contemporáneo, se convirtió en el espíritu del tiempo de la primera década del siglo XXI que, como ola de malestar psíquico, marcó el inicio económico del tercer milenio en el mundo.

${ }^{8}$ Critican países pobres de América Latina el actual modelo económico. (2008, 16 de noviembre). La Jornada, p. 19. 
El desorden mental que se creó en el terreno económico motivado por las ambiciones desmedidas provocadas por la codicia estructural de unos cuantos, y la autorregulación salvaje de la ley de la oferta y la demanda financiera, permitieron que se realizaran en la sociedad estadounidense y otras economías internacionales los movimientos financieros corruptos necesarios para obtener ganancias exponencialmente altas, a corto plazo, sin medir las consecuencias de dichas acciones. Tal tendencia no consideró que dicha práctica deshonesta pondría en el precipicio a la economía de los Estados Unidos, a la del mundo en general, y al sistema de desarrollo neoliberal en su conjunto. ${ }^{9}$

Esta situación creó en el ámbito financiero el "modelo de la economía de casino", cuyo motor no estuvo fundado en la producción de bienes materiales reales, sino en una "economía virtual" conformada por inversiones especulativas e imaginarias que no crearon riqueza material concreta, ni contaron con respaldos reales de capital efectivo que las sostuvieran, pero que en los balances financieros de las empresas sí reflejaron provisionalmente acumulación de ganancias virtuales. De esta forma, la economía de trabajo y de producción real fue sustituida por la economía ficticia de casino, dominando la dinámica de esta última sobre toda la organización económica, y de manera gradual tuvo lugar un largo círculo vicioso económico que generó, a largo plazo, el derrumbe del sistema financiero mundial.

Así, se creó una economía virtual que generó riqueza aparente sin contar con activos reales de respaldo que promovió el esquema del capitalismo salvaje, dando origen a la economía especulativa que infló las bolsas de valores y los derivados financieros, produciendo dinero virtual a través de un modelo de economía de casino artificial (Ríos, 2008, p. 35).

De esta manera, la enorme desregulación económica, la libre circulación monetaria y la liquidez total del capital financiero sin regulación ni fiscalización que se practicó durante muchos años, particularmente en el gobierno del presidente George W. Bush, permitió que se diera una gigantesca transferencia de capitales del sector productivo al terreno especulativo. Asimimso, se gestó un sistema económico cimentado en la sustitución del capitalismo productivo de los sectores primarios por la voracidad insaciable del capitalismo especulativo centrado en los objetivos mercantiles de los sectores terciarios, basado en una lógica autorreferencial de muy corto plazo, que promovió un sistema de intercambios financiero

${ }^{9}$ Tras un nuevo paradigma. (2008). Revista Siempre, 2888, 8-12. 
que buscó el incremento del valor de las actividades especulativas y en la gestión técnica de las diversas formas de alto riesgo.

Por otra parte, la reducción de los objetivos de los operadores financieros globales a un brevísimo plazo para obtener fuertes ganancias, redujo la capacidad de las finanzas para desempeñar su función de puente entre el presente y el futuro, con vistas a sostener la creación de nuevas oportunidades de producción y de trabajo a largo plazo (Concha, 2008, p. 14). En palabras del presidente de Brasil, Luiz Ignacio Lula Da Silva, se puede decir que

... los grandes bancos internacionales que antes calificaban a las economías del mundo, especialmente a las periféricas y le enseñaban a América Latina qué debía hacer en materia financiera, quebraron no por impedir la generación de empleos y de riqueza; sino por impulsar la especulación y el riesgo irresponsable. Esa práctica especulativa transformó a diversos sectores del sistema financiero en casinos, que perdieron en la ruleta y el mundo fue víctima del juego. ${ }^{10}$

De esta forma, la dinámica del nuevo capitalismo financiero en su fase neoliberal de inicios del siglo XXI borró drásticamente el espíritu económico inicial que, apoyado en la concepción de la ética protestante, colocó el trabajo directo y al ahorro como virtudes fundamentales para generar la acumulación originaria que posibilitó la forma de producción capitalista y la sustituyó por la dinámica de la especulación y la "aventura económica". Así, el contenido de esta mentalidad originaria privilegió como útiles "la moralidad, la puntualidad, la diligencia, la moderación, etcétera, porque son virtudes que proporcionan crédito" (Weber, 2006, p. 39). Derivado de esta subjetividad nativa surgió en el siglo XVIII La ética protestante del capitalismo, que en su momento se caracterizó por dar origen

... a esos nuevos empresarios que no eran sujetos especuladores osados y sin escrúpulos, naturalezas aptas para la aventura económica, como las ha habido en todas las épocas de la historia, ni tampoco siquiera gentes adineradas que crearon este nuevo estilo de vida oscuro y retraído, aunque decisivo para el desarrollo de la economía; sino hombres educados en la dura escuela de la vida, prudentes y arriesgados a la vez, sobrios y perseverantes, entregados de lleno y con devoción a lo suyo, con concepciones y principios rígidamente burgueses. (Weber, 2006, p. 59)

${ }^{10}$ Los bancos que enseñaban a AL qué hacer, ahora están quebrados: Lula”. (2008, 22 de septiembre). La Jornada, p. 29. 
Por consiguiente, en dicha época, "el tipo ideal" de empresario capitalista nada tiene que ver con ese tipo vulgar o afinado de ricachón: aquél aborrece la ostentación, el lujo inútil y el goce consciente de su poder; le repugna aceptar los signos externos del respeto social de que disfruta, porque le son cómodos; su comportamiento presenta más bien rasgos ascéticos y, sobre todo, no es raro, sino muy frecuente, hallar en él un grado de modestia mucho más sincera, que la recomendada en los discursos de Benjamín Franklin en los cuales postulaba que "nada de su riqueza la tiene para su persona, sólo posee el sentimiento irracional de cumplir buenamente con su profesión" (Weber, 2006, pp. 60-61).

En este sentido, "la idea peculiar del deber profesional, de una obligación que debe sentir el individuo [...] ante el contenido de su profesión, consista en que fuera lo que fuera, ésta es la característica más grande de la 'ética social' de la civilización capitalista, para la que posee una significación constitutiva” (Weber, 2006, pp. 41 y 42). Así, el más noble contenido de la propia conducta moral consistía, justamente, en sentir como un deber el cumplimiento de la tarea profesional en el mundo. Tal era la consecuencia inevitable del sentido sagrado del trabajo y lo que engendró el concepto ético-religioso de profesión; concepto que traduce

a todas las confesiones protestantes la idea que el único modo de vida grato a Dios reconoce no la superación de la moralidad terrena por medio de la ascesis monástica, sino precisamente por el cumplimiento en el mundo de los deberes que a cada cual impone la posición que ocupa en la vida y que por lo mismo se convierte para él en su profesión. (Weber, 2006, pp. 75-77)

El orden capitalista necesita la entrega a la profesión de enriquecerse; es una especie de comportamiento ante los bienes externos, de tal modo adecuado a esa estructura, que ya no es posible hablar hoy de una conexión necesaria entre ese comportamiento práctico "crematístico" y una determinada concepción unitaria del mundo. "La concepción del mundo va determinada por la situación de los intereses político-comerciales y político-sociales. Quien no adapta su conducta práctica a las condiciones del éxito capitalista se hunde o no asciende demasiado" (Weber, 2006, pp. 60 y 61$)$.

De esta forma, "no fue la afluencia del dinero lo que provocó esa nueva revolución, sino la introducción del nuevo espíritu, el espíritu del capitalismo. Así, las fuerzas de la expansión del capitalismo no residieron en el origen de las disposiciones dinerarias utilizables en la empresa, sino más bien sobre el desarrollo del espíritu capitalista" (Weber, 2006, pp. 60 y 61). En síntesis, el summun bonum de esta "ética" consiste en la adquisi- 
ción incesante de más y más dinero, "cumpliendo con la profesión y evitando cuidadosamente todo goce inmoderado" (Weber, 2006, p. 40).

Sin embargo, contrariamente a este antecedente histórico originario de la sociedad capitalista, en la fase moderna del crecimiento neoliberal la economía del capitalismo se fue al extremo contrario y

se convirtió en un casino, el capital dominó al mercado y la cosa dominó al ser humano. La economía internacional se convirtió en un casino planetario donde por momentos unos ganaban, pero también en otros todos perdieron cuando las fuerzas incontrolables de la ambición y la codicia se apoderaron de la mecánica económica. (Toledo, 2008, p. 28)

Así, en la estructura del casino-mundo todo lo sólido se desvaneció en el aire, provocando el sismo económico que hizo temblar a los capitalistas, al mercado, a las instituciones, a los economistas, a los funcionarios, a los políticos y a la cultura (Toledo, 2008, p. 26).

\section{El PROTOTIPO DE “COMUNICACIÓN CASINO”}

Para que pudiera funcionar a nivel material el "modelo de economía casino" en la fase avanzada del neoliberalismo salvaje, se requirió también contar a nivel ideológico con el respaldo y la actuación intensiva de sus correspondientes "valores" subjetivos y procesos de comunicación de casino. Así, paralelamente a la transformación económica especulativa se creó el "modelo de comunicación casino", que se basó en la creación y promoción constante de una mentalidad de valores bárbaros del capitalismo salvaje que respaldaron y movilizaron socialmente como una gran oportunidad de compra las "inversiones basura", los derivados financieros de alto riesgo y otros productos paralelos que durante varios años había generado este modelo económico especulador.

Dicho prototipo de comunicación neoliberal de "libre mercado informativo" se caracterizó por estructurarse con dos apoyos comunicativos culturales centrales: Por una parte, a través de los medios de difusión colectivos y otras infraestructuras de marketing bancario se crearon múltiples campañas de persuasión publicitaria para que los diversos públicos pudientes adquieran con grandes facilidades los paquetes económicos, fondos de inversión, instrumentos de deuda, montos de acciones compuestos por hipotecas subprime, "pirámides financieras", inversiones tóxicas, etcétera, que ofrecían engañosamente a los clientes grandes rendimientos bancarios a corto plazo. Y por otra parte, fomentó intensivamente, vía la estructura de los medios de difusión masivos, en especial de los canales electrónicos, 
una cultura cotidiana del consumo exacerbado basado en el gasto abusivo del monto de las tarjetas de crédito, la racionalidad light, la ausencia de pensamiento crítico, la información epidérmica, el narcisismo como éxito social, la mentalidad de la felicidad inmediata, la ganancia a corto plazo, la frivolidad desmesurada, la alimentación insaciable del "yo desatado", la atracción por el espectáculo escandaloso, la cultura de los efectos, el vicio por las experiencias adrenalínicas, la evasión permanente, etcétera, como sentido profundo de vida moderna y como modelo del éxito social que favoreciera a nivel subjetivo y material la expansión de ese modelo económico basado en la especulación y las apuestas bursátiles.

De esta manera, los principales multimillonarios causantes de la "burbuja financiera" que cuando explotó arrastró al mundo a la recesión económica, inmersos en dicha cultura de la frivolidad neoliberal adquirían la lista de productos más exóticos del consumo superfluo internacional. Mediante ello, en los últimos años se multiplicaron las selectas boutiques que alcanzaron ciudades nunca soñadas como Pekín, Shangai, Estambul, Río de Janeiro, Moscú, Yakarta, Bombay, Panamá, entre otras.

En poco tiempo, los multimillonarios crecieron a un ritmo de $8.5 \%$ anual, consumiendo los artículos más privilegiados para intentar calmar su deseo insaciable de lujo lujurioso como jets de nueva generación, autos deportivos exclusivos, palos de golf inimaginables, joyas espectaculares, obras de arte deslumbrantes, instrumentos musicales únicos, zafiros y rubíes gigantes, damas y caballeros de compañía, escusados de oro, diamantes gigantes, masturbadores autorregulables, pieles de animales en peligro de extinción, pipas platinadas, sombreros aerodinámicos, vajillas de creación restringida, tinas llenas de vino y helado, etcétera, a precios alcanzables sólo por la súper élite financiera internacional. Para ello, se creó una cultura exclusiva que permitiera que la microclase adquiriera, por ejemplo, la edición limitada del jarrón veronese creado por el conocido fabricante de cristal italiano, Venini; la muy esperada nueva fragancia para mujeres que destila toques de flor de naranja y mandarina, lanzada por Prada; el navegador GPS de mano, por si el cliente desea esquiar o escalar; el USB más potente y rápido cuya parte trasera semeja las nalgas de una vedette famosa; el sofisticado reloj Blancpain 1735 con un costo de lista de un millón de dólares; el enorme yate Annaliese surcador de mares que cuenta con cine, spa y helipuerto, con un precio de 103 millones de dólares; el güisqui con sabor a frutas oscuras y especias con toques de madera, cuya botella se conseguía por tan sólo 38 mil dólares; el caviar extraído de un esturión de 80 años proveniente del mar Caspio y envasado en oro de 24 quilates, con un costo de 24 mil dólares el kilogramo; la taza de café más exquisita del mundo que se obtiene de los excrementos de los civetos de Indonesia, 
criatura arborícola que se alimenta de las cerezas de café y cuyos intestinos le dan un toque único al sabor del aromático, con un precio de mil 200 dólares el kilo (Toledo, 2008, p. 26); las 49 piezas de chocolate del exclusivo sello libanés Patchi, envueltos en seda en una caja de piel de gamuza con divisiones de oro y platino, coronada con flores de cristal Swarovski, cuyo precio es de cinco mil libras esterlinas, ${ }^{11}$ etcétera.

Así, a través de los medios de difusión colectivos y otras infraestructuras mercadológicas surgió el impulso de una fuerte cultura generalizada de la avaricia, el consumo superfluo y la frivolidad sistémica que legitimó y promovió a nivel subjetivo cotidiano la expansión del "modelo de la economía basura", hasta que explotó por ser insostenible su realidad ficticia.

En este sentido, con el respaldo institucional, administrativo y cultural que durante mucho tiempo se cimentó en el terreno financiero, se logró que una clase cleptocrática ${ }^{12}$ tomara el control de la economía, con el fin de remplazar el capitalismo industrial, por un capitalismo artificial de especulación, que con apoyo de infraestructuras computarizadas persiguió el objetivo de realizar las transacciones virtuales más veloces y cuantiosas de toda la historia económica, para obtener rápidas ganancias a costa de lo que fuera, impulsando el modelo del "capitalismo de casino" que nunca fue regulado por el Estado, hasta que reventó la realidad insostenible del nuevo "paradigma chatarra" (Modak, 2008, p. 16).

\section{El RECUENTO GLOBAL DE DAÑOS}

La severa crisis material global se inició paulatinamente en el ámbito financiero de los Estados Unidos al producirse el colapso de la "burbuja inmobiliaria" en el año 2006, y se propagó rápidamente en 2008 a todas las economías europeas, asiáticas, latinoamericanas y africanas, ocasionando una profunda recesión mundial que generó una megapérdida de la enorme riqueza construida durante varias generaciones, y arrastró a todo el sistema capitalista a una profunda debilidad económica histórica (Millán, 2008, p. 25). Así, este crac del modelo neoliberal comenzó en los Estados Unidos con el caos del sistema hipotecario a través de la quiebra de las grandes compañías hipotecarias Freddie Mac, Fannie Mae, etcétera. Posteriormente, afectó al sistema financiero estadounidense con la quiebra de los bancos Lehman Brothers, Merrill Lynch, Bear Stearns, Morgan Stanley, HBos, Goldman Sachs, Washington Mutual, Bank of America, Citi-

${ }^{11}$ En Londres lanzan la caja de chocolates más cara del mundo. (2008). La Jornada, p. 10 .

${ }^{12}$ Sector social que se dedica a robar y abusar del resto de la sociedad como forma sistemática de vida. 
group y otros más. Después afectó al sector de coberturas con la insolvencia de la compañía de seguros más grande del mundo: American International Group. Y más adelante, se irradió a todos los ámbitos económicos y sociales del planeta. ${ }^{13}$

Este proceso desencadenó un efecto de quiebras en cadenas que afectó a todos los sectores de la economía internacional y desembocó en la severa recesión mundial de 2008. Como ya se mencionó, tal colapso derrumbó las principales instituciones bancarias, de seguros, hipotecarias, crediticias, de bienes raíces, automotrices, industriales, autopartes, de consumo, electrónica, etcétera, y estuvo a punto de convertirse en una crisis recesiva superior a la de la Gran Depresión de los años veinte, con repercusiones desastrosas inimaginables para todos los países del orbe.

En este sentido, el radical colapso global no sólo fue una crisis de Wall Street, sino fue el quiebre de todas las calles del mundo, que demandó la transformación profunda de toda la arquitectura del sistema económico internacional, para crear una nuevo orden financiero que no esté basado en la especulación, la corrupción, la amoralidad y los "valores casino", sino que se cimiente en la sana productividad, la regulación del Estado, la supervisión de instituciones civiles y los valores culturales de la sobrevivencia colectiva.

\section{EL RESCATE DEL ESTADO NACIÓN}

La existencia de esta crisis global que enfrentan las sociedades contemporáneas demuestra que entramos en un nuevo periodo histórico donde el proyecto de desarrollo neoliberal del mercado, con su filosofía del "fin de las ideologías", llegó a sus límites de aplicación y, paradójicamente ahora, es urgente repensar el rescate ineludible de la función del Estado como instancia rectora del proceso de crecimiento global colectivo, pues la dinámica de oferta y demanda por sí misma demostró contundentemente que es incapaz de regular de manera equilibrada los procesos de crecimiento y ordenamiento sociales. De aquí la necesidad urgente de preguntarnos: En esta etapa de fuerte descomposición social, ¿cuál debe ser el papel del Estado para construir una política de comunicación colectiva que permita el avance equilibrado y no la simple subordinación subjetiva a los modelos monopólicos de la acumulación nacionales e internacional de capital? ¿Cuáles son los nuevos valores para la sobrevivencia colectiva que debe impulsar y proteger el Estado para existir armónicamente en contra de los valores salvajes que promueve el mercado desregulado?

${ }^{13}$ Profunda crisis económica mundial en 2008, Moral y Luces. Recuperado el 28 de octubre de 2008, de la página web http://moralyluces.wordpress.com 
Ante esta realidad, es indispensable que el Estado rescate su máxima función rectora en el campo de la información y la cultura nacional frente a la dinámica salvaje que han alcanzado las fuerzas del mercado como poderes fácticos en este ámbito, para construir un nuevo proyecto de comunicación y espiritualidad colectivo basado en la participación de las comunidades. En este sentido, es necesario que se replantee el viejo pacto desequilibrado de desarrollo de comunicación existente entre el Estado, los monopolios y la sociedad, para orientarlo hacia un nuevo acuerdo tripartita de participación ciudadana que equilibre el actual funcionamiento desigual del viejo modelo de crecimiento del mercado que nos ha llevado a la creación de un orden social bárbaro que modificó los contenidos y las fronteras límites del desarrollo sistémico. Es por ello que, dentro de este contexto histórico de crisis del sistema global, ahora cobra una relevancia capital volver a retomar la reflexión elemental sobre el papel del Estado nación en la construcción y conducción del proceso de comunicación colectivo, pues el proyecto de comunicación mercado que se aplicó durante varias décadas, creó la profunda catástrofe económica, política, cultural, ideológica, ética y espiritual que viven las economías modernas.

Por este motivo, en el contexto histórico de la crisis global más fuerte que se ha experimentado desde los años treinta del siglo XX, debemos examinar el margen de fuerza que posee el Estado para enfrentar el colapso global que encaran las comunidades internacionales derivado del tsuna$m i$ económico, financiero y social internacional que enmarca el nacimiento del siglo XXI.

\section{LA REFORMA CULTURAL ÉTICO-MORAL}

No obstante la intervención sustantiva del Estado en la esfera económica para solucionar la mayor crisis del modelo capitalista neoliberal desde la Gran Depresión de 1930, es necesario destacar que estas acciones no son suficientes para resolver las contradicciones profundas que le dieron vida al crac económico, sino que para solventar dicho colapso, también es fundamental que se corrijan las causas culturales de naturaleza ético moral que le dieron origen. Asimismo, es primordial asimilar que dicho fenómeno de quiebra económica tuvo su origen en la acumulación de una mentalidad especulativa que se practicó a los extremos de la avaricia y la codicia sin límites institucionales, que después se reflejó a nivel material. De no enfrentar la situación de la manera que aquí se plantea, el Estado sólo habrá atacado los efectos más visibles de este desplome social y no las causas profundas que le dieron vida y, en consecuencia, dicha ceguera mantendrá vivas las causas recónditas que originaron tal 
colapso civilizatorio planetario, y en los próximos años se volverá a repetir, pero con mayor intensidad.

En este sentido, frente al profundo colapso de la economía mundial a inicios del tercer milenio, es central entender que la verdadera corrección de este nuevo hundimiento económico sistémico, en última instancia, no se arreglará con la simple inversión de multimillonarios fondos para los rescates bancarios, con la devolución de impuestos a los ciudadanos por el Estado, con la inyección de préstamos de emergencia, con la creación de nuevas reglas de supervisión, con la reactivación del crédito, con el otorgamiento de subsidios extraordinarios a las empresas colapsadas, con el descenso sustantivo de las tasas de interés del bono del Tesoro estadounidense hasta niveles sin precedentes, sino que en el fondo, únicamente se solucionará en la medida en que se sanen las raíces profundas que le dieron vida de manera lenta y silenciosa.

De esta forma, siendo que la naturaleza de esta crisis sistémica global es muy compleja, los mecanismos de remediación deben considerar propuestas a nivel económico, pero también cambios fundamentalmente a nivel éticomoral, pues fue en este nivel social donde se originó el conflicto. Así, por una parte, se deben contemplar las enmiendas económicas, y por otra parte, las opciones culturales para resolver tal terremoto civilizatorio.

Por ello, además de considerar la aplicación de todas las medidas económicas oportunas de salvamento, para comprender con profundidad el origen de esta nueva crisis moderna de dimensiones globales, es necesario reconocer que conjuntamente al agotamiento de los tradicionales ciclos económicos que formula la teoría económica clásica, ahora debemos aceptar la existencia de potentes ciclos de valores culturales que de forma muy eficiente influyen ética y moralmente sobre el comportamiento de los sujetos económicos, en especial sobre los administradores de los sistemas financieros. Y es que estas estructuras ideológicas afectan de manera profunda la operación de los ciclos económicos materiales para que éstos entren en fases de expansión o de desmoronamiento estructural.

Todo esto hace necesario que además de asimilar y resolver en última instancia este conflicto financiero que desarticuló todas las estructuras económicas de las sociedades del mundo contemporáneo,también se requiere ir al fondo ideológico moral del espectacular crac de inicios del tercer milenio. Ante ello, es imperioso aceptar que esta crisis global que tuvo su mayor visibilidad a través del estrepitoso derrumbe económico mundial, en el fondo fue una drástica crisis de valores culturales, morales y de visiones esenciales de la vida, que llegaron a su límite extremo de aplicación anárquica. Por consiguiente, para resolverla, también se necesita realizar una profunda reforma moral de las cosmovisiones y comporta- 
mientos salvajes de las sociedades modernas, en especial las occidentales, que es donde anidó el virus mental que provocó el sismo civilizatorio mundial (Esteinou, 1998, 2002, 2004 y 2006).

Debido a esta realidad, para resolver este conflicto en sus raíces sistémicas, es indispensable, por una parte, que se modifique la promoción de los "valores culturales salvajes" del neocapitalismo contemporáneo, que impiden el sano equilibrio económico internacional; y por otra, que a través de la acción del Estado y de la sociedad civil organizada se regrese a la creación y fomento de los nuevos valores mentales sustentables para la sobrevivencia colectiva armónica, de lo contrario, sólo se habrán atendido los efectos materiales superficiales de corto plazo de este derrumbe económico, pero estará plenamente vivo el germen cultural axiológico comunicativo que le dio vida a dicha quiebra civilizatoria, y en los próximos años se volverá a repetir el fenómeno del crac económico, político, ecológico, social, ideológico y comunicativo, con consecuencias mayores.

Bajo estas circunstancias, la humanidad no habrá aprendido y corregido la clara lección para la historia moderna que dejó la crisis de los "valores culturales basura" que dieron vida al "modelo de la economía basura" en las sociedades capitalistas modernas de la primera década del siglo XXI. Con ello, los conglomerados humanos permanecerán en completa desprotección ante el desarrollo futuro, pues dicho fenómeno, nuevamente, se refrendará como si la historia no hubiera existido.

\section{FUENTES CONSULTADAS}

Bendesky, L. (2008, 22 de diciembre). ¿Qué sabemos de la crisis? La Jornada. Blanco, J. (2008, 23 de diciembre). Tragedia y farsa. La Jornada.

Cela, José Camilo. (2008). También el capitalismo se murió. Revista Siempre, 2887.

Concha, M. (2008, 27 de diciembre). Mercados, sociedad civil y estados. La Jornada.

De León, I. (2008, 23 de septiembre). La culpa no fue de Milton sino de Alan. Noticiero Digital (www.noticierodigital.com).

Esteinou Madrid, Javier. (1998). Crisis económico-política, cultura y reforma moral (Octava Semana de la Investigación Científica. Cuadernos de Extensión Universitaria). México, D.F.: Universidad Autónoma Metropolitana, Unidad Xochimilco.

__. (1996, 3-5 de septiembre). Crisis, valores y reforma moral (tres partes). Excélsior.

- (2002, septiembre). El triunfo de la cultura idiota. Revista Etcétera. Una Ventana al Mundo de los Medios (Nueva Época), 23. 
(2004). Los medios de información y el triunfo de la cultura idiota. Revista Información Pública, 1, (II).

(2006). La rentabilidad de los medios de comunicación de servicio público. (Documento interno). México, D.F.: Consejo de Programación/ Radio Ciudadana/Instituto Mexicano de la RadioIMER/Segob/SEP.

Galindo, M. (2008, 2 de noviembre). Ha muerto la dictadura del mercado. Revista Siempre, 2890.

Millán, J. (2008). Para entender la turbulencia, Revista Siempre, 2886.

Modak, F. (2008). La danza de los millones en Estados Unidos. Revista Siempre, 2886.

Ríos, A. (2008, 28 de diciembre). El principio del fin. Revista Siempre, 2898.

Santa Cruz, J. (2008, 5 de octubre). Washington y Wall Street premian la corrupción. Revista Siempre, 2886.

Toledo, V.M. (2008, 6 de noviembre). ¿Tiembla el capitalismo? La Jornada.

Weber, M. (2006). La ética protestante y el espíritu del capitalismo (Colección Ensayo). Buenos Aires: Caronte. 